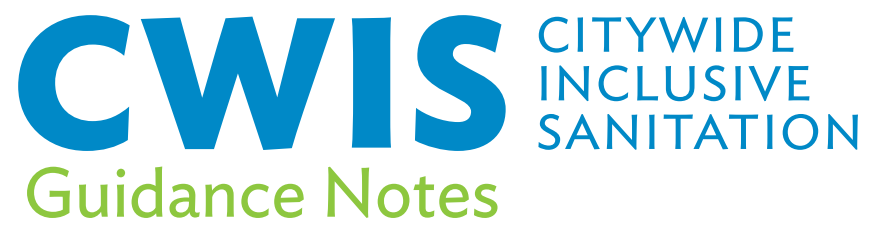

The Citywide Inclusive Sanitation (CWIS) Guidance Notes aim to share essential knowledge to embed CWIS principles in planning and delivering sanitation services to developing member countries of the Asian Development Bank (ADB). These easy-to-understand learning materials are prepared by Water Sector Group of ADB, and structured along the ADB project processing cycle. They can be used to advocate and share the benefits of CWIS to all stakeholders.

\title{
Inclusive Financial Mechanisms: Improving Access to Sanitation Services for Poor Households
}

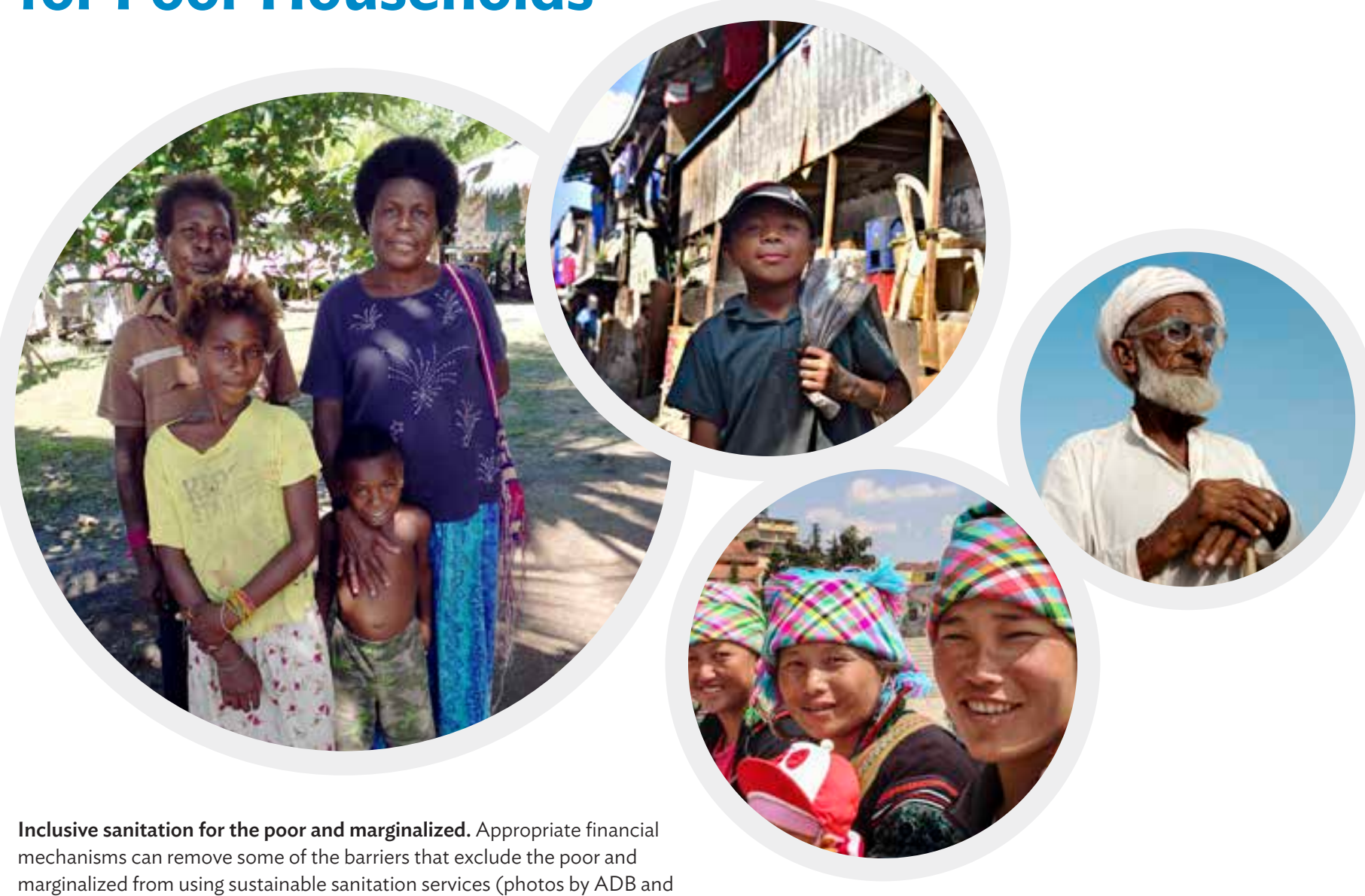
Penelope Dutton).

\section{Challenge: Designing Sanitation Services That Include Poor Households}

Citywide Inclusive Sanitation (CWIS) means that everyone, including people who are poor and marginalized, has access to sustainable sanitation services. However, poor households have limited funds and may prioritize food, education, and other household expenditure over sanitation.
Even when motivated to invest in sanitation, high costssewerage connection charges, toilet hardware-and large recurrent costs, such as septic tank desludging or monthly sewerage tariffs, can be major barriers to inclusive sanitation. 
The Operational Priority for Poverty Reduction of the Asian Development Bank (ADB) aims to reduce inequality in opportunity and remove the barriers for the poor and vulnerable in accessing quality infrastructure and services. Funding for sanitation is usually limited and needs to be utilized effectively, to reach those most in need of support.

Financial mechanisms may be employed solo, or in combination, depending on the needs of poor households; the timing of financial support in the sanitation chain; and the local context (e.g., policies, culture, and financial environment) (Box 1). There is no perfect financing mechanism, and all must be carefully monitored to ensure they achieve the proposed objectives. The three key considerations in applying a financing mechanism are: ${ }^{1}$ (i) cost-effectiveness of the financing mechanism,

(ii) potential for market distortion, and

(iii) potential for cheating or perverse outcomes.

\section{B O X 1}

\section{Financing Mechanism Requirements}

Financing mechanisms should

- Be appropriate to the context.

- Be sensitive to the needs of poor households.

- Be targeted, equitable, fair, and transparent.

- Align with poverty policies and programs.

- Not distort the market.

- Be free from political interference.

Source: Penelope Dutton.

\section{Identifying and Targeting Poor and Marginalized Households}

Targeting poor people is essential to ensure scarce resources are used effectively for the benefit of those in most need. Poor households are those in the low-income bracket, frequently relying on informal sector incomes. They often include persons with disabilities, elderly people, or households headed by women. Other vulnerable groups in the Asia and Pacific region include indigenous peoples, ethnic minorities, migrants, and internally displaced and/or conflict-affected people.

Targeting poor households can be achieved through several methods, such as identifying geographic locations populated by widespread or large pockets of poor, vulnerable, and disadvantaged people; informal settlements; areas with inadequate sanitation (and water supply) services, or no service at all; or by identifying those households within an existing service area that are not participating in the services.

With the aid of household surveys or censuses, poor households can be identified based on household income relative to the poverty line, wealth ranking (determined by household assets), or through affordability or willingness to pay analyses. National identification systems such as the
ID Poor registry of poor households in Cambodia, or other social registrations, e.g., clients of the Department of Social Welfare and Development in the Philippines, can be used to systematically identify and target poor and vulnerable households.

Where there is no formal identification system, those most in need of financial support can be identified through informal approaches: nongovernment organizations (NGOs) that work with and know the community well; community-based organizations such as the Women's Union in Viet Nam that identified poor and near-poor women eligible for septic tank credit; and community leaders and community self-identification of its members most in need.

The ADB Nepal Small Towns Water Supply and Sanitation Sector Project used water users' associations, municipalities, and the community to identify poor and vulnerable households eligible for toilet hardware subsidies and sewerage connection subsidies through participatory assessments. ${ }^{2}$ The list of households was made publicly available and beneficiaries validated through random surveys.

1 Willet, J., and B. Powell. Financing sanitation: Finding a middle path to reach the poor Learning Brieffrom the East Asia Regional Learning Event. Civil Society, Water, Sanitation and Hygiene Fund and DFAT, 2016.

2 ADB. Nepal: Small Towns Water Supply and Sanitation Sector Project. 
Technology can also help, such as using remote sensing and street view data in Luanda, Angola, to develop a poverty map to improve targeting. ${ }^{3}$ Poverty predictions using mobile phone metadata may also be possible. ${ }^{4}$ In choosing a method of identifying the poor, there is usually a trade-off between the cost of accurately identifying the poor and the extension of financial support to some in society that do not need it-known as "leakage." A practical balance needs to be struck between high-precision poor identification methods in a particular context and the risk of leakage.

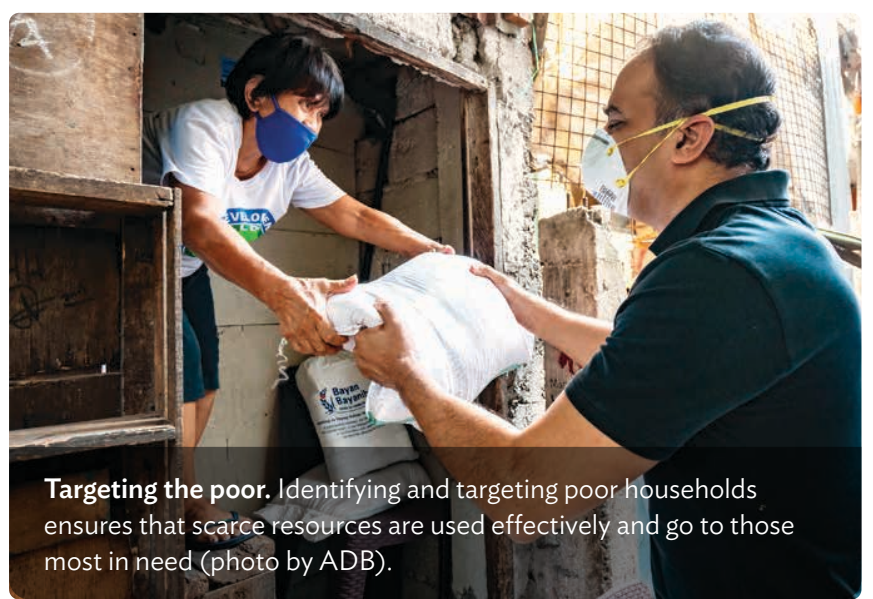

\section{Financing Sanitation Access for Poor Households (Capital Investments)}

Connecting to sewerage or networked systems, and building improved or new household toilets and communal toilets incur large capital costs. These costs can be a major barrier for poor households due to their low income, lack of affordable options, limited space, or because they are tenants who do not own their land or house. For households with disabled or elderly family members, toilets may require additional modifications for functionality, increasing the cost further for these households with high support needs and low-income earning potential.

This section provides six financing options to increase the inclusion of poor and vulnerable households (Figure 1).

Figure 1: Options for Financing Sanitation Capital Costs for Poor Households
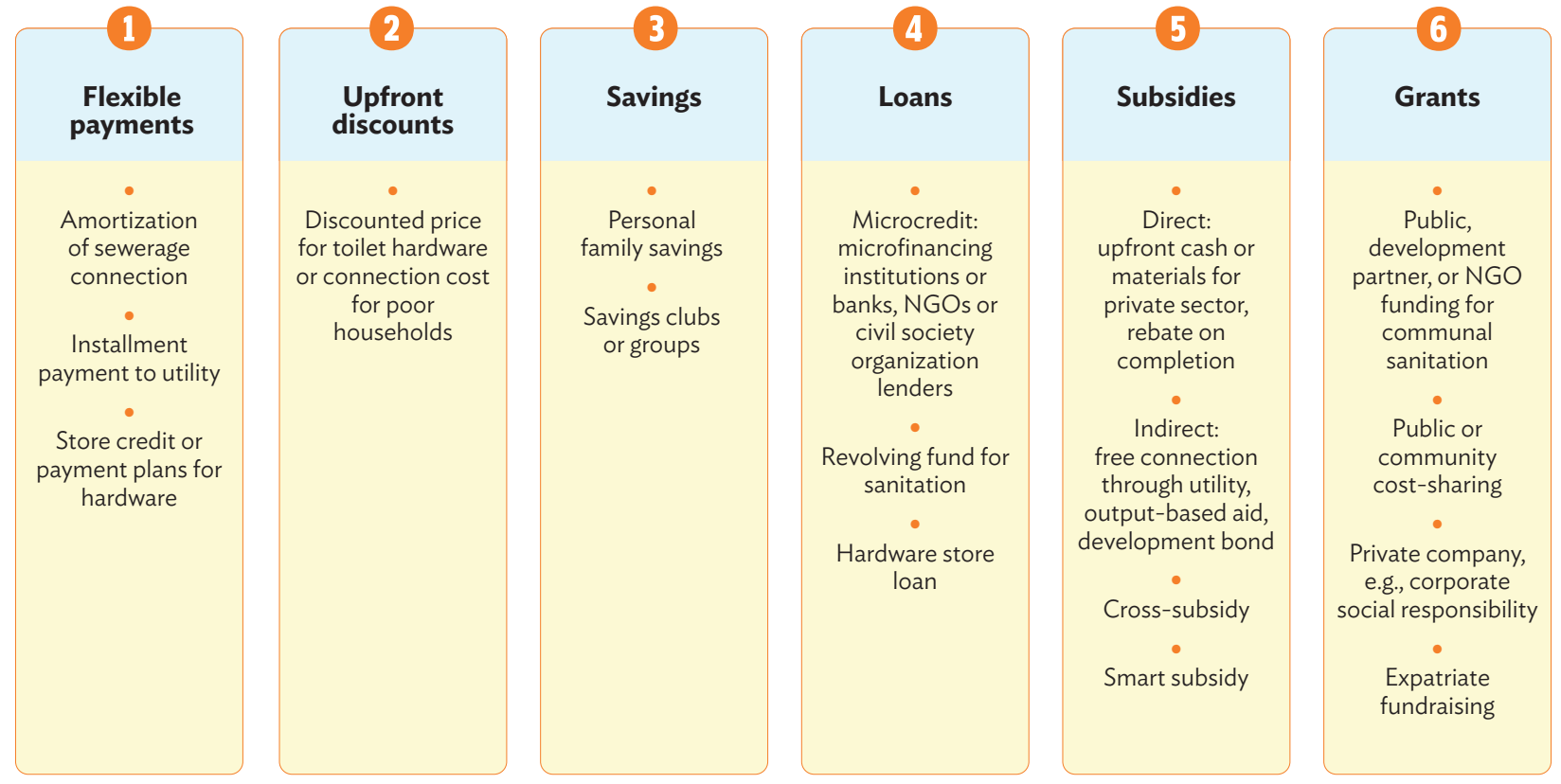

NGO = nongovernment organization .

Source: Penelope Dutton, based on C. Sijbesma. 2011. Sanitation financing models for the urban poor. Thematic Overview Paper 25. (online) The Hague: IRC International Water and Sanitation Centre November. www.irc.nl/top25.

3 L. Andres et al. 2019. Doing More with Less: Smarter Subsidies for Water Supply and Sanitation. Washington, DC: World Bank.

4 J. Blumenstock, G. Cadamuro, and R. On. 2015. Predicting poverty and wealth from mobile phone metadata. Science. 350 (6264). $1073-1076$. 


\section{Flexible payments}

Utilities can assist poor households to connect to networked systems by amortizing the connection costs into sewerage charges over a longer payment period. Utilities can also allow households to pay sewerage connection costs in small installment payments over a year or two so that the initial outlay for households is smoothed.

\section{Upfront discounts}

Poor and vulnerable households can receive discounts for sewerage connection charges or sanitation hardware, particularly if they are registered as poor.

\section{Savings}

Savings groups or clubs can provide solidarity and support for poor households to practice daily, weekly, or monthly saving toward sanitation investments. Often, this is led by women, for example, in the Pacific, Women's Savings Clubs set up by Live \& Learn International in Fiji, Papua New Guinea, Solomon Islands, and Vanuatu buy and build their toilets in informal settlements. ${ }^{5}$ While empowering for women, the capital in savings clubs may be small and addressing sanitation can be slow.

\section{Loans}

Microcredit through banks, credit unions, and microfinancing institutions (MFIs) are effective at supporting sanitation for the poor. Examples include Bangladesh's Grameen Bank loans to women for toilets, and MFIs in the Philippines providing toilet loans with capital supported by water.org.

Microcredit allows households to make sanitation improvements and then repay these over 1 or several years in easy-to-pay installments. Microcredit programs have demonstrated that many poor households are willing to take loans to finance their sanitation assets and also consistently repay these loans.

Some MFIs may need persuading to take on sanitation in their business and be convinced that the poor will borrow for sanitation. Initial loan guarantees may be needed from $A D B$ or seed funding from the government as in the case of

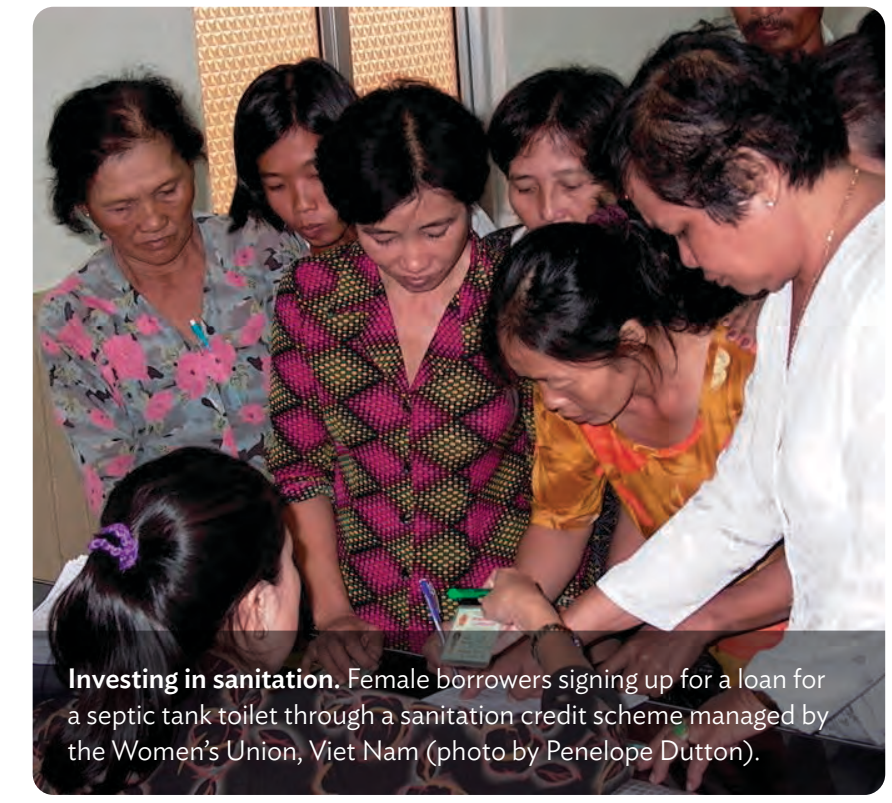

the Vietnam National Social Development Bank. ${ }^{6}$ Formal MFIs serve poor households better than informal money lenders who have exorbitant interest rates and sometimes coercive repayment practices. ${ }^{7}$

Sanitation loans can be income-enhancing for the poor and help reduce lost income and medical costs due to poor health which can, in turn, boost their revenues and give them the ability to repay loans. Loan facilities must be tailored for the poor with flexible repayment frequency and methods (e.g., mobile money which is suitable for small payments), low documentation requirements, low-interest rates, and removal of guarantor and unrealistic collateral requirements (e.g., house ownership). Loans are not appropriate for the very poor.

Sanitation revolving funds or sanitation credit schemes have been successful in Viet Nam, where many women's unions have helped thousands of households to invest in their septic tank toilets through low-interest, no-collateral sanitation revolving funds, initially capitalized by multilateral funds.

Repayments are used to extend access to credit for septic tanks to other beneficiaries, pay overheads, and grow the fund. Examples include the World Bank's Three Cities Sanitation project, the Government of Australia's Three

5 Western Pacific Sanitation Marketing \& Innovation Project. https://www.youtube.com/watch?v=HSfSPXnqP4U.

6 C. Sijbesma. 2011. Sanitation financing models for the urban poor. Thematic Overview Paper 25. (online) The Hague: IRC International Water and Sanitation Centre November. www.irc.nl/top25.

7 M. Robinson. 2001. The microfinance revolution: sustainable finance for the poor. IBRD/World Bank. 
Delta Towns Project, and the ADB Central Region Urban Environmental Improvement Project. ${ }^{8}$ A revolving fund was established to fund some household sanitation in the ADB Sanitation, Public Health and Environment Improvement Project in Kiribati, however, due to limited supervision, borrowers did not always spend loans on sanitation.

\section{Subsidies}

Direct subsidies can be made to targeted households to cover the upfront sewerage connection costs or household sanitation hardware (as cash or materials). Rebates-which provide cash reimbursement to the household after toilet construction or sewerage connection-are a form of subsidy (Box 2).

Indirect subsidies are directed at utilities or local governments. ADB projects can require "free" sewer connections, with the cost of connecting all households to sewerage systems within a service area included in the project. This strategy can encourage higher connection rates by all households, particularly if marketed as a one-time

\section{BOX 2}

\section{Direct Subsidy}

A payment direct to households or individuals. Payment may be in the form of cash, vouchers, or tax credit. Households or individuals then use the subsidy either to pay for anything or for specified goods and services.

Source: B. Evans, C. van der Voorden, and A. Peal. 2009. Public Funding for Sanitation: The many faces of sanitation subsidies. Water Supply \& Sanitation Collaborative Council.

limited offer by utilities, with the benefit of increased flows to sewage treatment plants. Poor households in the service area are automatically included, but should be helped to connect to the sewerage system including house connection modification. Effective delivery of performance-based indirect subsidies through output-based aid (OBA) or payment by results for poor (PBR) and vulnerable households has evolved in the ADB Nepal Second Small

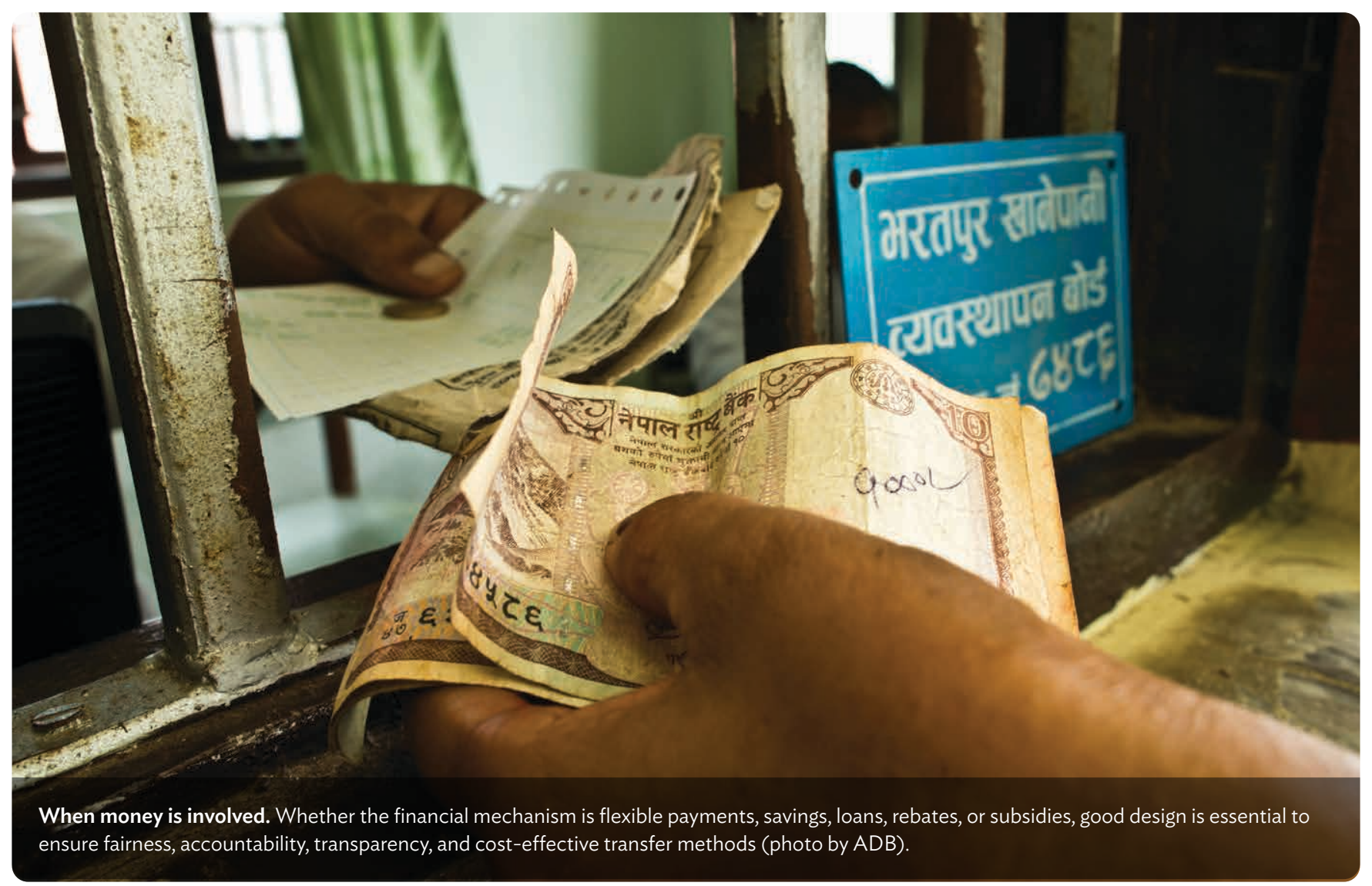

8 S. Tremolet, P. Kolsky, and E. Perez. 2010. Financing on-site sanitation for the poor - A six country comparative review and analysis. Water and Sanitation Program, World Bank; Asian Development Bank. 2014. From toilets to rivers: Experiences, new opportunities, and innovative solutions. Manila: Asian Development Bank. 
BOX 3

\section{Output-Based Aid}

Output-based aid (OBA) is a type of results-based funding designed to increase access to and delivery of more inclusive infrastructure and social services through the use of performance-based incentives, rewards, or subsidies. Payments are made on the delivery of specific services or "outputs," e.g., the number of poor households connected to the sewer network.

A third-party service provider (public or private) is contracted for service delivery and receives a subsidy to complement or replace the contribution required of users. The service provider prefinances the project and is reimbursed only after the services or outputs have been delivered and fully verified by an independent agent. If not properly designed, OBA can generate perverse incentives such as pursuit of connections without associated services.

Source: L. Andres et al. 2019. Doing More with Less: Smarter Subsidies for Water Supply and Sanitation. Washington, DC: World Bank.

Towns Water Supply and Sanitation Sector Project, and strengthened under the ADB Nepal Urban Water Supply and Sanitation (Sector) Project where it was agreed to use the OBA process for providing household latrines with the eligible households (poor, poor and headed by women, and vulnerable) as beneficiaries. Grants are given to service providers after delivery of the household connections or the construction of toilets ( $90 \%$ subsidy) has been verified by an independent verification agent. OBA and PBR have been adopted by the government as an approved approach. OBA and PBR have been used widely for sanitation in Cambodia and Viet Nam, and in Bangladesh, the World Bank has funded an OBA subsidy to MFIs to help them develop sanitation products and extend their reach to the poorer households (Box 3).

An extension of the OBA performance-based indirect subsidy is Sanitation Development Impact Bonds (DIBs). This arrangement focuses on longer-term outcomes and is being trialed in Cambodia to reduce the high rates of open defecation in rural areas. The DIB structure incentivizes the impact investor and the implementer to work together to achieve outcomes, using adaptive management techniques based on evidence from the program. ${ }^{9}$
Other subsidy incentives include linking connections to water supply, which is a higher priority for most households, with the provision of a free toilet; or if the household builds a toilet, they receive a free or subsidized household water connection. However, such incentives may not be available to households that rent their houses (Box 4).

Cross-subsidies can include utility water charges used to pay for sewerage connections or the development of on-site sanitation. Community cross-subsidies can be mobilized so that the more affluent members of a community use their resources (cash or labor) to support poor households to achieve sanitation objectives for the benefit of all. The NGO Gram Vikas has used socialized community fundraising to improve sanitation (toilets and bathrooms) in villages in Odisha, India. All households in the village contribute cash or in kind to the village fund, based on their ability to pay, to cofinance sanitation improvements and water supply (footnote 8 ). Community-based approaches require some community cohesion, which may not be present in every urban context, but have worked in urban wards of Viet Nam. ${ }^{10}$

Smart subsidies supporting the sanitation market and product development (not the product directly) can help the poor by reducing the capital costs of toilets and offering a wider choice of affordable options. Examples include one-stop shops supplying a toilet installation packagematerials, pit digging, construction - which results in economies in labor provision and lower cost, or low-cost toilet systems such as the Easy Latrine in Cambodia.

When water supply and sanitation subsidies fail to achieve their objectives, it is usually due to poor design. Subsidies may be pervasive, expensive, poorly targeted, nontransparent, and distortionary in the sanitation market, sometimes by crowding out other more effective and targeted funding.

The efficacy and efficiency of subsidies can be improved through (i) better targeting of the poor and vulnerable with transparent processes and by ensuring recipient checks are in place, (ii) making subsidies conditional on performance or service delivery, and (iii) decoupling subsidies from service access and consumption charges.

Cash transfers paid directly to beneficiaries rather than through an intermediate service provider avoid distortionary impacts on service providers and perverse

9 iDE. 2019. World's First \$10 Million Sanitation Development Impact Bond Launches. Press release. 18 November.

10 Author's experience, Australian Agency for International Development (AusAid) Three Delta Towns Project, Viet Nam. 


\section{B OX 4}

\section{A Word on Tenants and Landlords}

A problem with subsidies for household sanitation facilities is that the subsidy may benefit landlords and not tenants, through increased property values. Landlords may use increased property values as an opportunity to increase rents, which could force poor tenants to relocate to cheaper housing that may not have access to improved sanitation services. Where poor people are renting housing, which is not unusual, landlords need to be targeted directly and incentivized to make investments in sanitation, with accompanying protection to ensure that current tenants benefit from improvements.

Approaches to improve tenants' access to sanitation services include subsidies for shared sanitation facilities which prioritize live-in landlords, and landlords' guarantee that their tenants have full access to the subsidized facilities (Naivasha, Kenya); landlords give up a percentage of their land for the subsidized construction of improved sanitation infrastructure (informal settlements in Nairobi, Kenya); new rental housing bylaws which require landlords to provide sanitation facilities for their tenants (Antananarivo, Madagascar); and the use of service models which are suitable for areas with high tenancy rates, e.g., shared pay-per-use sanitation (BEST Indonesia).

Source: L. Andres et al. 2019. Doing More with Less: Smarter Subsidies for Water Supply and Sanitation. Washington, DC: World Bank.

incentives to gain subsidies. Since the service provider cannot depend on direct transfers from the government to make up any funding gaps, its focus and accountability is on meeting the needs of the customer (footnote 3).

\section{Grants}

In situations where there is high density, insecure land tenure, and a high number of renters, public or communal sanitation blocks may be necessary. Grants for the construction of these facilities may involve $100 \%$ public or development partner financing, or cost-sharing by the community and local government, and/or NGO. In Nepal, for public sanitation services such as community toilets, fecal sludge management, decentralized wastewater treatment, and stormwater drains, local bodies or water users and sanitation committees jointly contribute $15 \%$ of the capital cost and the government contributes $85 \% .^{11}$

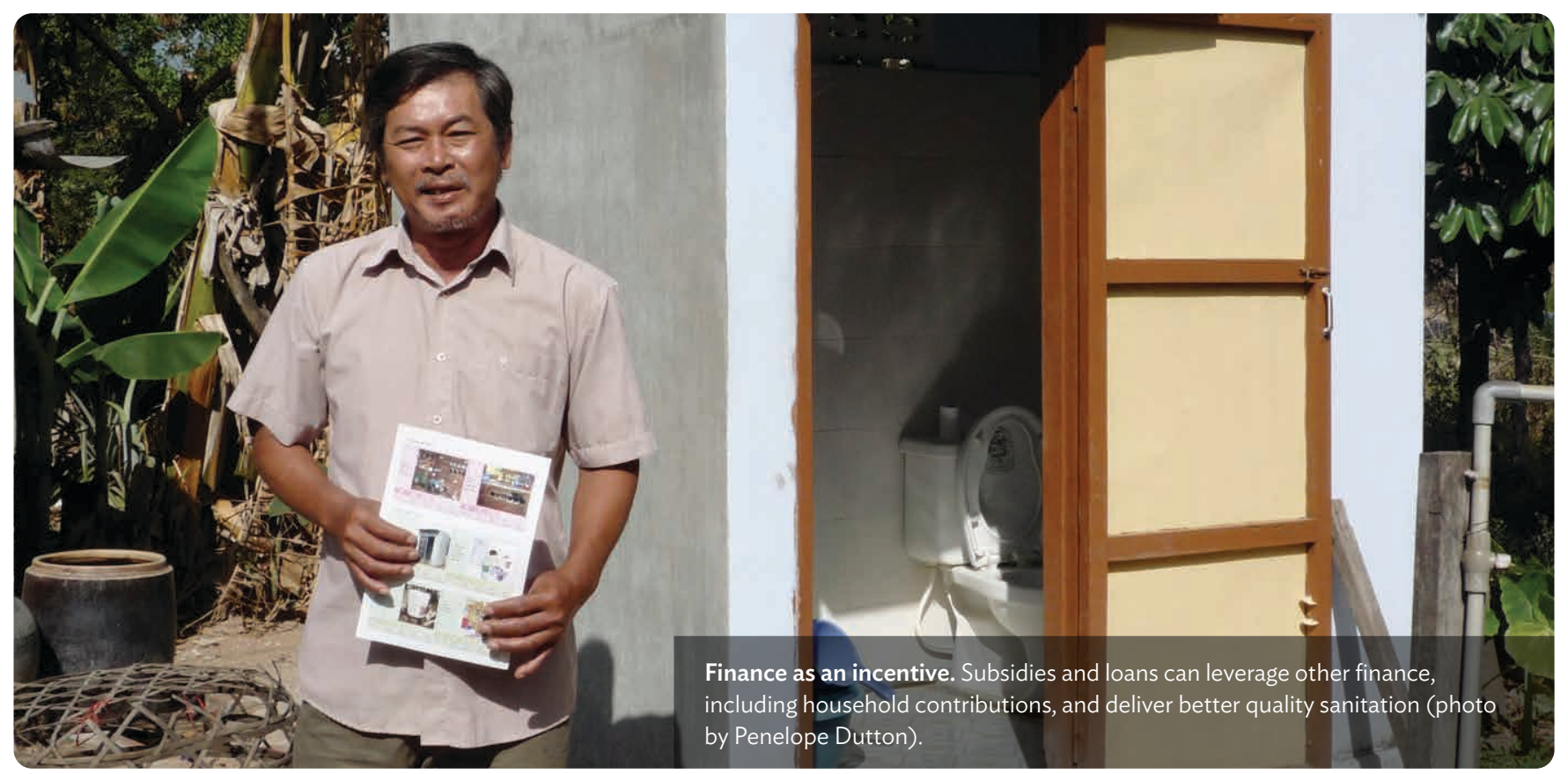

11 N. Pokhrel and S. Adhikary. 2017. Tapping the Unreached. Nepal Small Towns Water Supply and Sanitation Sector Projects: A Sustainable Model of Service Delivery. Manila: ADB. 
In Pune, India, the municipal government provided $100 \%$ of investment funds to NGOs to construct and then operate public sanitation blocks, resulting in a 50\% savings compared to contractor-built facilities due to the elimination of kickbacks to engineers and councilors (footnote 6). Grants can leverage other funding for the poor through corporate social responsibility projects, especially in countries where this is mandatory, e.g., India and Indonesia. Expatriate fundraising may also contribute significantly, as in the case of Sulabh toilets in India (footnote 6).

\section{Financing Services Provision for Poor Households (Recurrent Costs)}

Beyond access to sanitation services, poor urban households may require additional support to ensure affordable consumption of sanitation services further along the sanitation chain, such as sewerage or wastewater treatment, septic tank and pit-emptying costs, and payment to use communal sanitation facilities (Box 5).

B OX 5

\section{Ways of Financing Recurrent Costs}

- Lower-cost technology

- Differential pricing

- Sanitation surcharges

- Direct subsidies

- Pay-per-use

- Subscriptions models

- Operational subsidies

Source: Penelope Dutton.

An important consideration for service affordability for the poor is the use of appropriate technology with low operating costs. This can help keep regular wastewater fees in check. For example, Indonesia's Community Sanitation Program (SANIMAS) in Denpasar, Bali Province installed decentralized anaerobic baffled reactor plants for treating domestic wastewater. This decentralized system is cheap to run and only requires simple maintenance. User fees are reasonable for the poor and cover all operation and maintenance costs (footnote 9).

For sewerage services, utilities might consider differential pricing in their tariffs. One example is a social block tariff where high-volume wastewater producers pay more for sewerage services than those who produce less wastewater, even though each group benefits equally from the operation of the sewerage network and treatment plant. This assumes that poorer households consume less water and, therefore, generate lower volumes of wastewater. A social tariff discounts the tariff for poor households with the difference financed through cross-subsidies or public financing. Tariffs differentiated by customer category can be of limited use if all tariffs charged are below the cost of the service.

In Bangladesh, fecal sludge management businesses operate a differential pricing model to facilitate services to low-income customers. This is achieved by an internal cross-subsidy, with higher prices charged to those with larger pits or septic tanks, so that low-income households are served at affordable rates. ${ }^{12}$

Linking wastewater charges with water charges is possible including by adding a percentage for wastewater to increasing block tariffs for water. However, this method discriminates against large households and households with shared connections. ${ }^{13} \mathrm{~A}$ flat sanitation surcharge can be added to the water bill for sewerage or non-sewered sanitation services. This regular low-tariff collection, combined with scheduled desludging of septic tanks, can help the poor access desludging services (India, Indonesia, the Philippines, and Viet Nam).

In some cities in Indonesia, the water utility manages septic tank desludging as a service and charges a small "wastewater fee" as part of the monthly water bill. The customer simply calls the utility to have their septic tank desludged then the utility collects the sludge at no additional cost. The impact of surcharges and cross-subsidies may be limited for the poor if they are not connected to water supply (or sewerage) systems (footnote 3 ). ${ }^{14}$

12 Water \& Sanitation for the Urban Poor (WSUP). 2019. Triggers for growing a sanitation business aimed at low-income customers: Experience from five cities. Water and Sanitation for the Urban Poor. Stone Foundation.

13 Global Water Partnership. 2016. Beyond Increasing Block Tariffs- Decoupling water charges from the provision of financial assistance to poor households.

14 Water \& Sanitation for the Urban Poor. 2012. Sanitation surcharges: a way forward for financing pro-poor sanitation? 


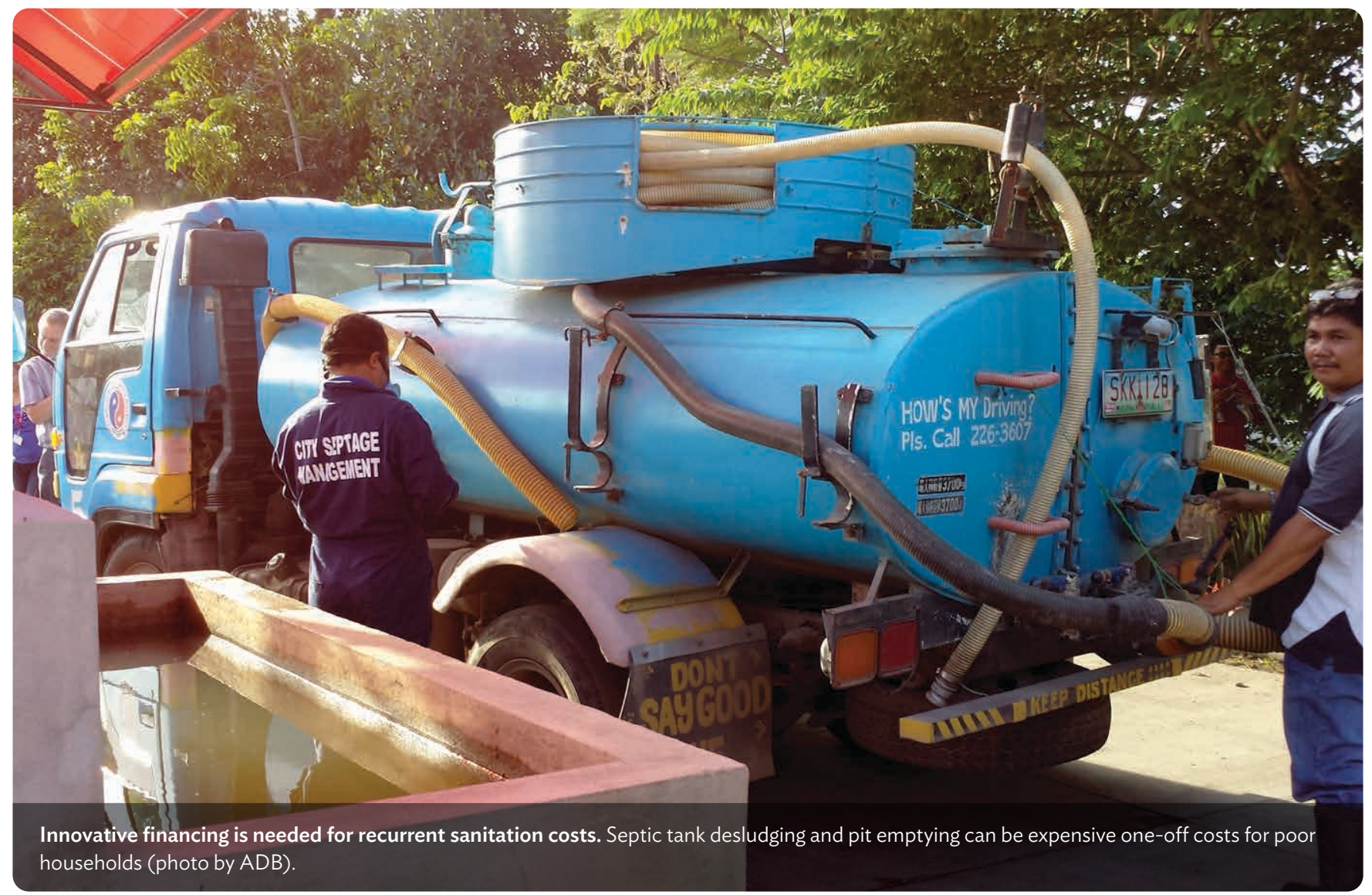

Direct subsidies to the poor for sanitation consumption services may be delivered through conditional cash transfers, often through a country's welfare payment system. In the People's Republic of China, the local city government is responsible for a direct subsidy to poor households every month so that they can make monthly payments to the utility for wastewater treatment (or water supply or solid waste management). The water utility is obliged to provide sewerage services to the whole city area as requested by the city government and does not have the option of differential pricing to support the poor. ${ }^{15}$ With electronic banking, conditional cash transfers can be received by targeted individuals into their bank account, providing recipients with flexibility and convenience to cash their payments through agents, ATMs, and point-of-sale machines. ${ }^{16}$

The pay-and-use approach for communal sanitation facilities is common and inexpensive. Examples include
Ghana for toilets; Kenya for toilets and showers; and Indonesia for toilets, bathing, and laundry facilities (footnote 8). The pay-per-use (single-use) approach can be effective in some contexts, and a subscription modelfor unlimited use or an agreed number of visits over a fixed time period, usually a month -is also possible, as is a combination of the two. ${ }^{17}$

In many Indian cities, Sulabh adopted a pay-per-use approach to maintain community sanitation complexes catering to poor and low-income areas. In Vanuatu, urban families pay for communal sanitation each month based on the family composition, with less charge for children. The money is deposited into the account of a women-led sanitation committee and then used for cleaning materials and septic tank desludging. ${ }^{18}$ For sustainability, communal sanitation charges need to be set to cover costs, including staff, as volunteers are generally not sustainable (footnote 6).

15 Meeting notes. Hisaka Kumira, sector team leader, Private Sector Operations Department, ADB. 24 June 2020.

16 ADB, 2019. Strategy 2030 Operational Plan For Priority 1 Addressing Remaining Poverty and Reducing Inequalities, $2019-2024$.

17 Used together in Tamil Nadu, India to accommodate transient and permanent residents (footnote 6).

18 ADB Port Vila Integrated Urban Improvement Project, design consultations. 


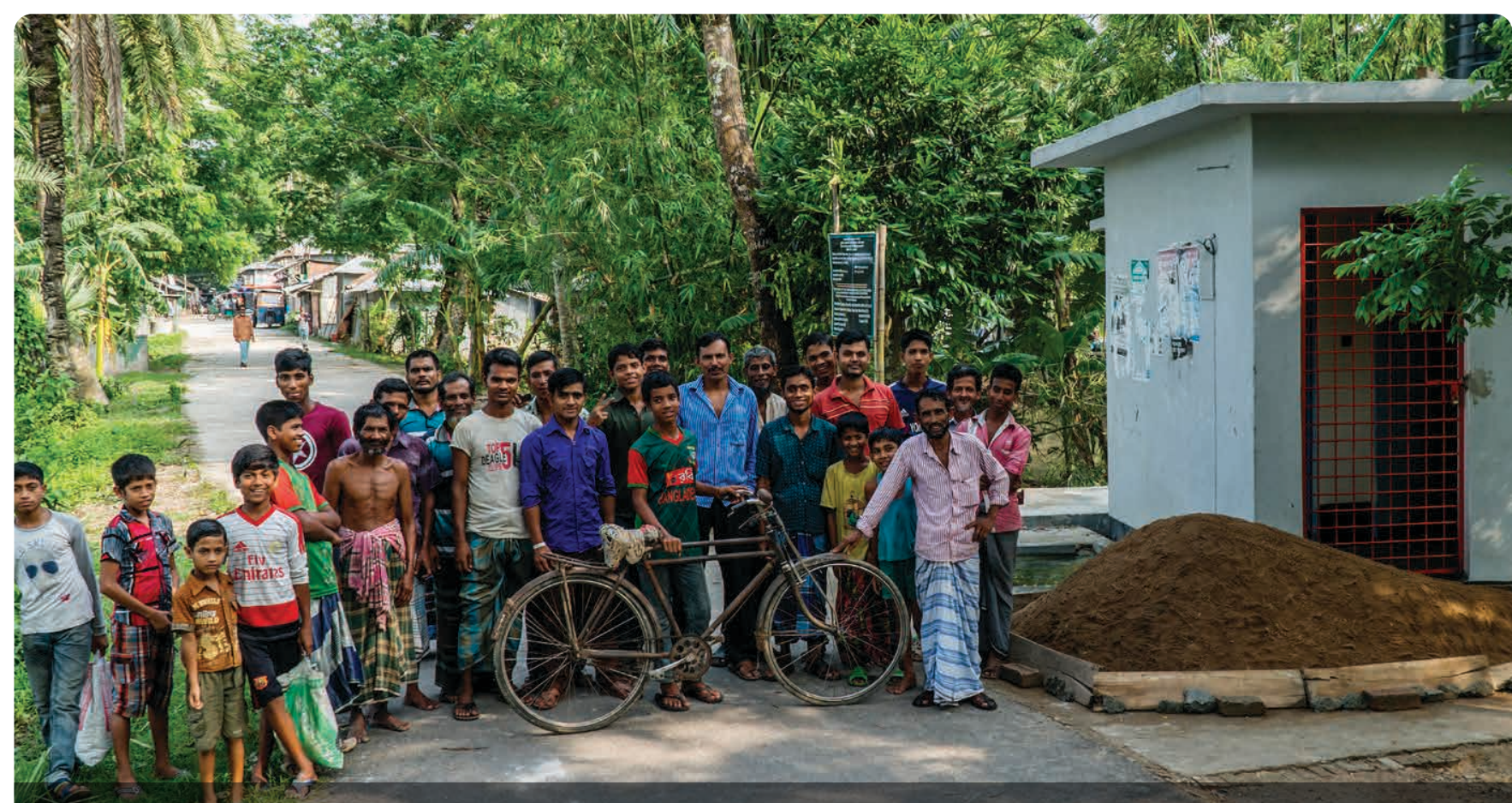

Recurrent costs of communal sanitation. Community sanitation blocks, such as this new facility in Bangladesh, need appropriate financing for ongoing operation, cleaning, and repairs (photo by ADB)

Indirect operational subsidies directed at sanitation entrepreneurs can help them develop their businesses to better serve the poor. These subsidies, potentially used for training and business development services (such as business planning, accountancy, and auditing) and purchasing equipment, can bring down the operating costs of small sanitation enterprises..$^{19}$ Operational subsidies may also be used to sustain communal sanitation through municipal funding of water supply, electricity, septic tank desludging, or sewerage fees.

\section{Some Steps to Success}

Applying financial mechanisms to ensure that poor households benefit from sanitation projects can be achieved by following a process (Figure 2 ).

The existing urban sanitation context and costs of sanitation need to be analyzed, together with identifying who are the most disadvantaged and vulnerable groups who need financial assistance to access sanitation services.

Behavior change communications and information is essential to stimulate demand for sanitation and appreciation of the benefits.

Those groups who need support and their wider communities must be involved in determining the appropriate financial mechanisms for sanitation, for example, affordable sanitation hardware, repayment plans, subsidy mechanisms, and targeting of poor households. This involvement helps ensure proposed financial mechanisms are fit-for-purpose and acceptable.

Well-designed financial mechanisms need transparent and accountable methods for determining who benefits, and how finance is fairly distributed.

19 B. Evans, C. van der Voorden, and A. Peal. 2009. Public Funding for Sanitation - the many faces of sanitation subsidies. Geneva, Switzerland: Water Supply \& Sanitation Collaborative Council. 
Figure 2: Practical Steps to Make Financial Mechanisms More Inclusive

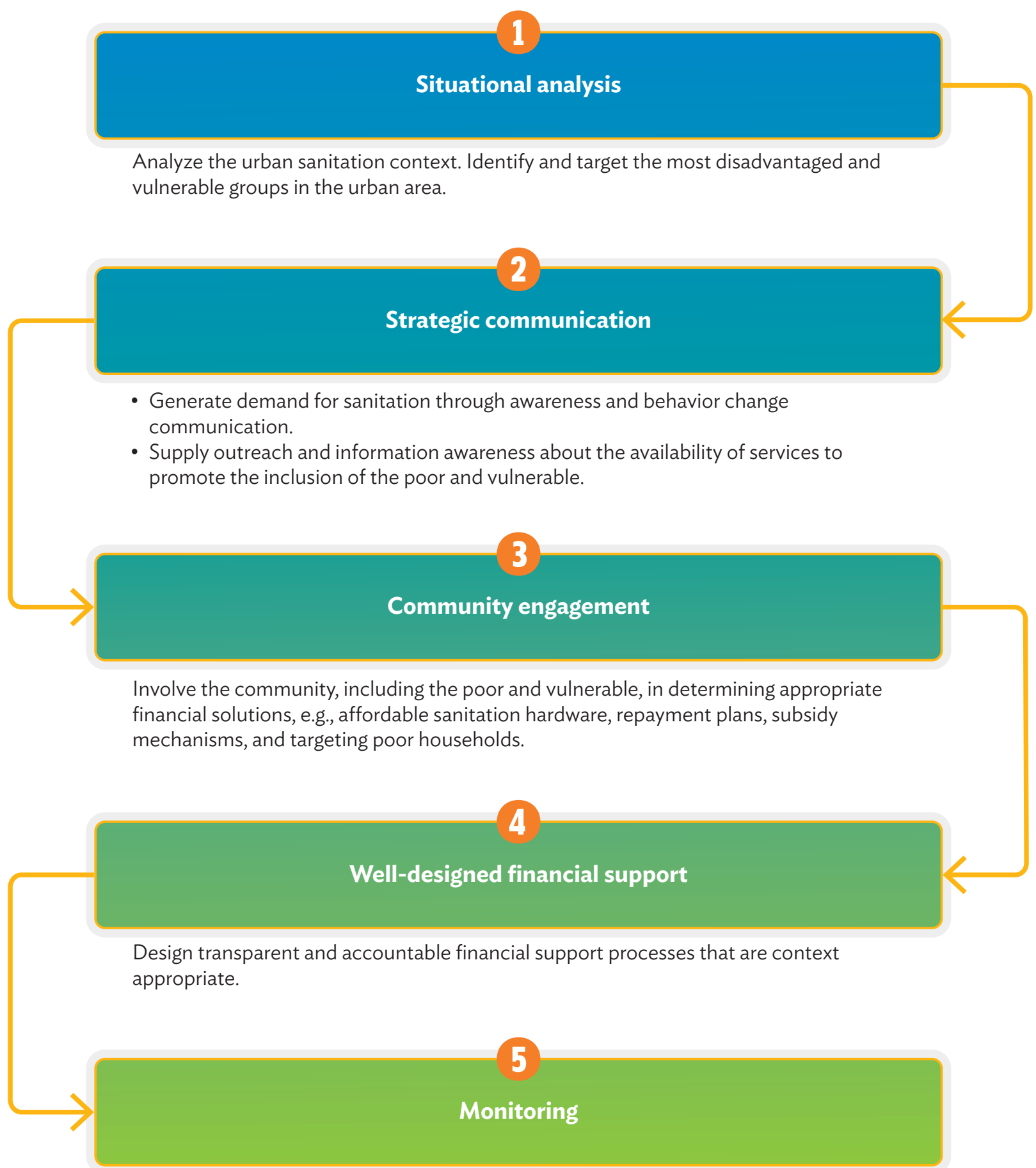

Monitor and evaluate the effectiveness of financial mechanisms at achieving the inclusion of the poor in sanitation access and consumption.

Source: Author, based on C. Sijbesma. 2011. Sanitation financing models for the urban poor. Thematic Overview Paper 25. (online) The Hague: IRC International Water and Sanitation Centre November. www.irc.nl/top25. 


\section{BOX 6}

\section{Outreach and Information}

In India, the Kolkata Municipal Corporation social development unit goes house to house to ensure every household in the sewerage service area has a connection, and informs households about installment schemes and subsidies for poor households (see the Kolkata Environment Improvement Project).

In Nepal, social mobilizers explain the output-based aid framework to target beneficiaries, including the level of grant, method of payment, extent of coverage, latrine models and costs, process of delivery of sanitation services, and the responsibility of the household (see the Nepal Urban Water Supply and Sanitation [Sector] Project).

Source: Asian Development Bank.

Once the financial mechanisms are available, information has to be provided on eligibility, how to access support, and the terms and conditions. To ensure information reaches target communities and households, appropriate communication methods will be needed including potentially outreach and home visits.
The effectiveness of any financial mechanism to support sanitation for poor households will only be known through robust monitoring processes. The key evaluation question to be considered is: has the financial mechanism(s) resulted in improved access to sanitation services by the intended target group?

\section{About the Asian Development Bank}

ADB is committed to achieving a prosperous, inclusive, resilient, and sustainable Asia and the Pacific, while sustaining its efforts to eradicate extreme poverty. Established in 1966, it is owned by 68 members -49 from the region. Its main instruments for helping its developing member countries are policy dialogue, loans, equity investments, guarantees, grants, and technical assistance.

Further Reading

SWA Finance Ministers Handbook, Water \& Sanitation: How to Make Public Investment Work 2020.
Follow us on social media

ff ADBWater

in adb-water

y) adbwater

water@adb.org

\section{$\mathrm{ADB}$}

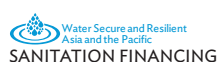

SANITATION FINANCING

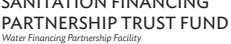

BILL \& MELINDA GATES foundation

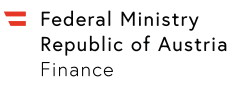

Federal Ministry
Republic of Austria Finance

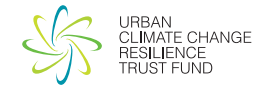

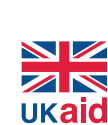

UKaid

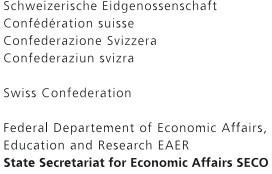

Swiss Confederation Federal Departement of Economic Affairs, State Secretariat for Economic Affairs SECO

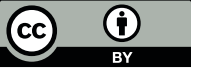
(c) $2021 \mathrm{ADB}$.

The CC license does not apply to non-ADB copyright materials in this publication. https://www.adb.org/terms-use\#openaccess http://www.adb.org/publications/corrigenda

ADB recognizes "Vietnam" as VietNam.
ISBN 978-92-9269-077-9 (print)

978-92-9269-078-6 (electronic)

Publication Stock No. TIM210394-2

DOI: http://dx.doi.org/10.22617/TIM210394-2

\section{Contact}

Asian Development Bank 6 ADB Avenue, Mandaluyong City 1550 Metro Manila, Philippines +63286324444

+63286362444

water@adb.org 